\title{
Reduction EMI of BLDC Motor Drive Based on Software Analysis
}

\author{
Navid Mousavi, ${ }^{1}$ Tohid Rahimi, ${ }^{2,3}$ and Homayoun Meshgin Kelk ${ }^{4}$ \\ ${ }^{1}$ Young Researchers and Elite Club, Islamic Azad University, Najafabad Branch, Najafabad, Isfahan, Iran \\ ${ }^{2}$ Electrical and Computer Engineering Faculty, University of Tabriz, Tabriz, Iran \\ ${ }^{3}$ Electrical and Avionic Engineering Faculty, Graduate Malek Ashtar University, Iran \\ ${ }^{4}$ Electrical Engineering Faculty, Tafresh University, Tafresh, Iran
}

Correspondence should be addressed to Tohid Rahimi; rahimitohid@yahoo.com

Received 15 October 2015; Revised 24 January 2016; Accepted 27 January 2016

Academic Editor: Anna Richelli

Copyright (c) 2016 Navid Mousavi et al. This is an open access article distributed under the Creative Commons Attribution License, which permits unrestricted use, distribution, and reproduction in any medium, provided the original work is properly cited.

In the BLDC motor-drive system, the leakage current from a motor to a ground network and existence of high-frequency components of the DC link current are the most important factors that cause conducting interference. The leakage currents of the motors, flow through common ground, will interfere with other equipment because of the high density of electrical and electronic systems in the spacecraft and aircrafts. Moreover, generally there are common DC buses in the mentioned systems, which aggravate the problem. Function of the electric motor causes appearance of the high-frequency components in the DC link current, which can interfere with other subsystems. In this paper, the analysis of electromagnetic noise and presentation of the proposed method based on the frequency spectrum of the DC link current and the leakage current from the motor to the ground network are done. The proposed method presents a new process based on the filtering method to overcome EMI. To cover the requirement analysis, the Maxwell software is used.

\section{Introduction}

Among different types of motors, the DC motors, due to their high starting torque, are still being used in many industries, especially in the aviation industry. Because of the brushes and mechanical commutation, high vibration may occur in DC motors. It should be mentioned that the brushless DC (BLDC) motors have the advantages of DC motors. For instance, due to the electrical commutation mechanisms, the BLDC motors also produce less vibration and acoustic noise. Therefore, the BLDC motors have been recognized as suitable alternatives for DC motors. The developments of technology in semiconductor devices have caused these devices to switch high currents or voltages at short time intervals [1]. Historically, the problem of electromagnetic interference (EMI) in the development and construction process was less regarded and discussed. In general, a product is designed based on the basic concepts of electromagnetic compatibility (EMC) and then tested from the standpoint of the EMC. If the product needs an additional filter or requires to be redesigned for meeting the EMI standards, the time and costs of the process of making the final product will significantly increase. For AC drives, these filters are not only accompanied with high costs, but also they occupy a large space. In order to reduce such costs and avoid their reconstruction, engineers must design strategies based on the EMI from the start of the production. Due to high $d v / d t$ and $d i / d t$, the EMI issue is caused by the flow of the parasitic current through different parts of the drive system [2].

EMI noise is divided into two parts: conductive and radiative noise. Radiation noise is emitted in the form of electromagnetic waves to space that is not discussed in this paper. The conductive electromagnetic noise flows through the common DC current or through parasitic elements and ground plane. The conductive EMI is divided into two types: common mode (CM) and different mode (DM). CM noise flows in the same direction on elements and returns via ground plane. DM noise flows in a direction on one element 
and returns via other elements. High $d v / d t$ is responsible for CM noise occurrence [3-5]. However, high $d i / d t$ is responsible for DM noise occurrence $[6,7]$.

Many researches about the EMI reduction and prevention of leakage current, especially for electric motors used in industries based on using the passive and active filters, have been centralized [8-14]. To implement simple and effective methods to overcome the EMI, Passive filters with large volume and weight system will be an indispensable part of the motor drive. References $[15,16]$ have proposed a process for the design of DC side filter to overcome noise. Similar to the process of designing filters for the DC side, a design process of AC side filter in [17] is presented. The mentioned references investigated proposed methods based on simple concepts of EMI emission based on laboratory samples or high-frequency models derived from practical tests. In [18], performance and size of the EMI filter with respect to the core material of inductance as a part of the filter structure are discussed. In [19], a new active common mode filter for inverter fed motors is presented. However, active filters require mainly a separate DC supply. In [5], a simple and new method is presented to design passive filters to reduce EM emissions in BLDC motor drives. With a focus on manufacturing technology, in [20], the EMI in Si insulated gate bipolar transistor (IGBT) and silicon carbide ( $\mathrm{SiC}$ ) junction field-effect transistor (JFET) based motor drives are compared. In fact, EMI resulted from the two types of power switches with new manufacturing technologies which are compared.

Hysteresis current control is widely used due to the simplicity of implementation and accurate and rapid response [21]. Meanwhile, in some applications, hysteresis controllers are used to improve performance and transient response of electric motors. In $[22,23]$, the hysteresis control methods are used to reduce torque ripple of the electric motors.

In this paper, a new process is presented in order to design filters based on the leakage current and the frequency components of the DC link current. This process can determine the size of the passive elements and their placements in BLDC drive structure. The analysis of electromagnetic noise and presentation of the proposed method based on the frequency spectrum of the DC link current and based on the leakage current from the motor to the ground network are done. The proposed method presents a new process based on the filtering method to overcome EMI. To cover the requirement analysis, the Maxwell software is used. The EMI reduction methods are applied to the high-frequency model of the BLDC motor drive. These models can be founded based on the experimental results or finite element analysis. In addition, the noise analysis is carried out in the case of hysteresis control.

\section{Characteristics of the Motor}

The proposed methods are investigated on a 33-watt, $10,000 \mathrm{rpm}$ BLDC motor drive. In order to implement the motor drive, the Maxwell circuit editor is used. According to the rotor position, the firing pulses of the power switches are ordered. Since the studied BLDC motor is of the outer
TABLE 1: Characteristics of the motor.

\begin{tabular}{lcc}
\hline Variable & Value & Unit \\
\hline Resistance per phase & 233.37 & $\mathrm{~m} \Omega$ \\
Back-EMF constant & 0.0156 & $\mathrm{~V} \cdot \mathrm{s} / \mathrm{rad}$ \\
Torque constant & 0.0154 & $\mathrm{Nm} / \mathrm{A}$ \\
\hline
\end{tabular}

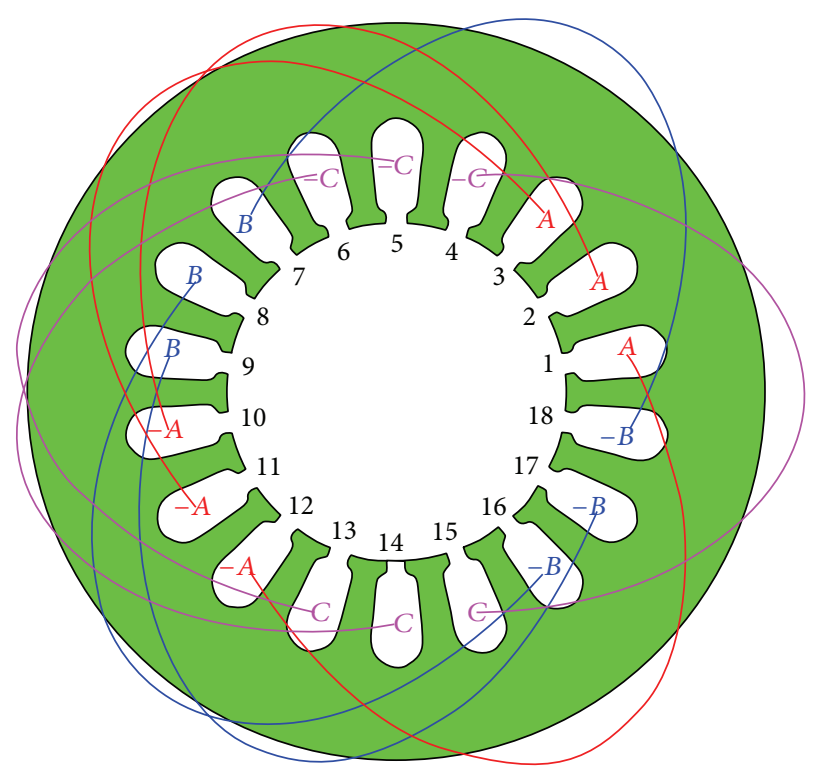

FIGURE 1: Motor winding scheme studied.

permanent magnet type, the self- and mutual-inductance variations are small.

It should be mentioned that one of the aims of the present paper has been to figure out the magnitude of the leakage current studding. Therefore, the effect of the inductance variations must be applied. The characteristics of the motor are summarized in Table 1 . The winding pattern of the motor is illustrated in Figure 1. The winding of each phase covers the whole circumference of the motor.

\section{The High-Frequency Model in the Circuit Editor}

The overall high-frequency model of the motor-drive system is shown in Figure 2. Each switch as well as each phase has high-frequency elements [24]. The parasitic capacitances of one phase can be connected to a scope. The waveform of this current is chosen as a waveform of the parasitic current. The high-frequency model of each phase is exhibited in Figure 3. The coils, named as $L_{\mathrm{a} 1}, L_{\mathrm{a} 2}$, and $L_{\mathrm{a} 3}$, provide the connection between the circuit editor and Maxwell software. The timevarying behaviors of the inductances and the back-EMF voltages appeared by means of the mentioned coils.

\section{The Proposed Procedure}

First, the motor-drive system without the use of filters is simulated in order to show the initial EMI level and 


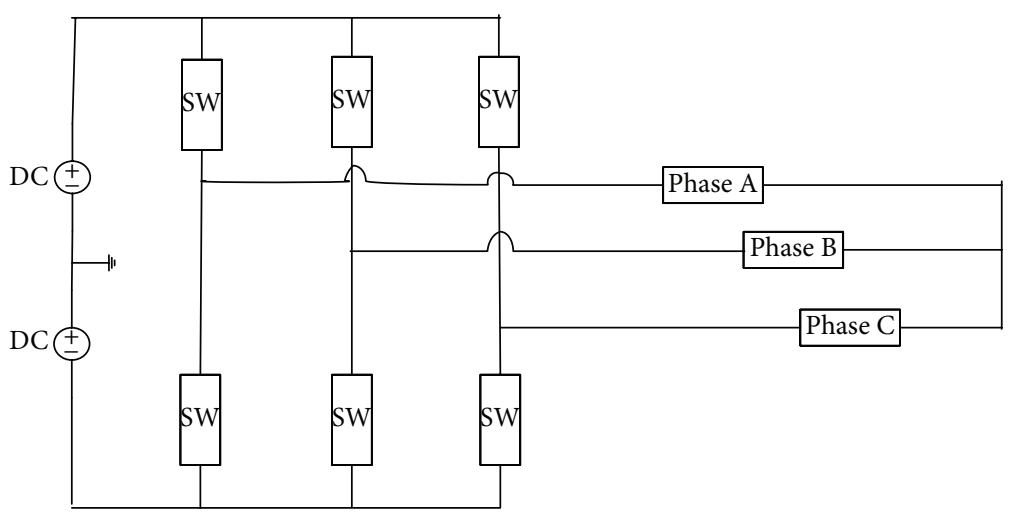

FIgURE 2: The overall high-frequency model.

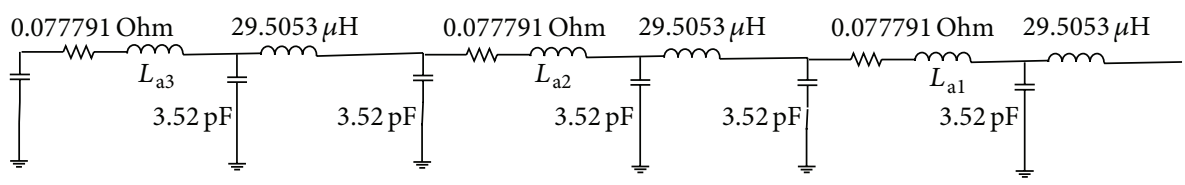

FIgURE 3: The high-frequency model of each phase.

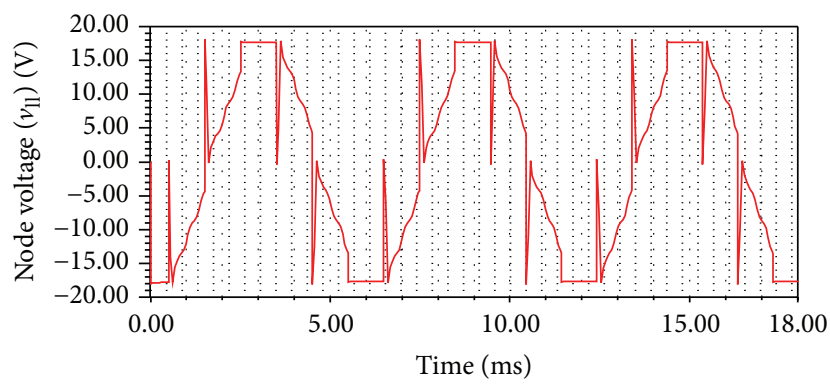

FIGURE 4: The line-to-line voltage waveform (without filter).

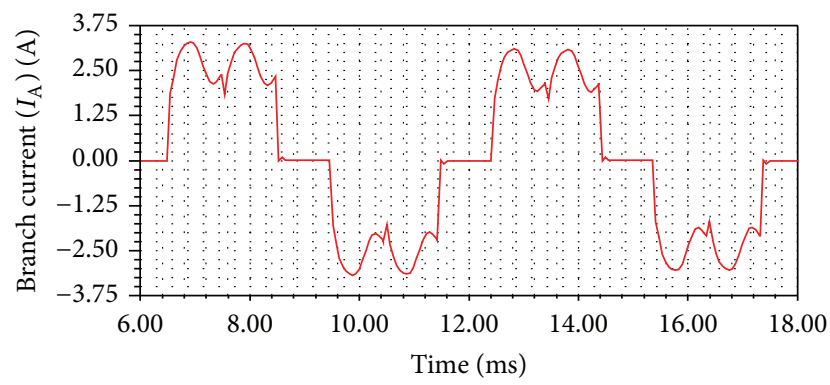

FIGURE 5: The phase current waveform (without filter).

the maximum amplitude of the leakage current. The high levels of the leakage current, sudden spikes in the motor terminal voltage waveform, and severe variations in the DC link current confirmed the necessity of using filters. The terminal voltage waveform, the phase current, the DC link current, the leakage current (motor to ground) waveform, and the FFT of the DC link current are shown in Figures 4-8, respectively. As observed in Figure 4, severe variations in line voltage have emerged. According to the concepts explained in

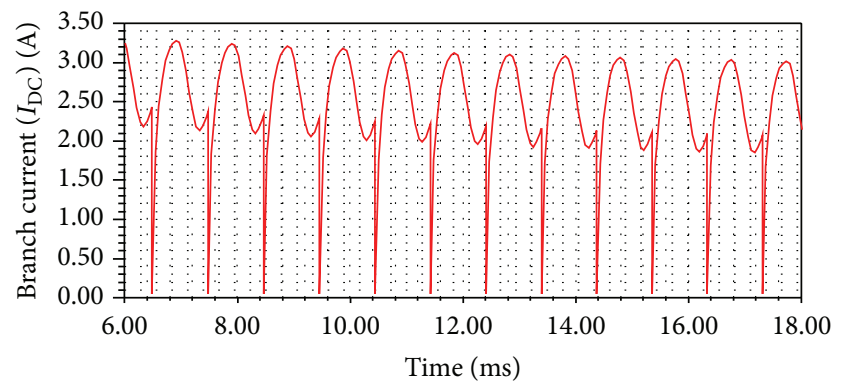

FIGURE 6: The DC link current (without filter).

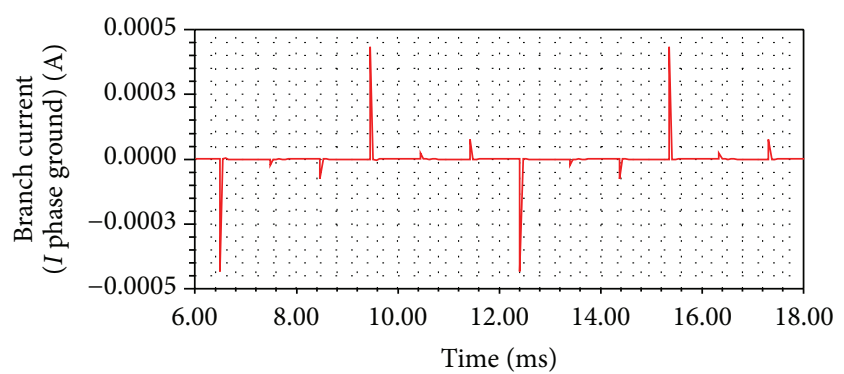

FIGURE 7: The leakage current (without filter).

the introduction section, the high variations in the BLDC motor terminal voltage are the reason for the ground leakage current.

The high-frequency components of the DC side current (see Figure 8) provide the conducted EMI. The conducted EMI progressed through the common DC bus and has an adverse effect on the other electrical systems that are fed from the common DC bus. This problem is more important in satellite and submarine systems. The conducted noise is 


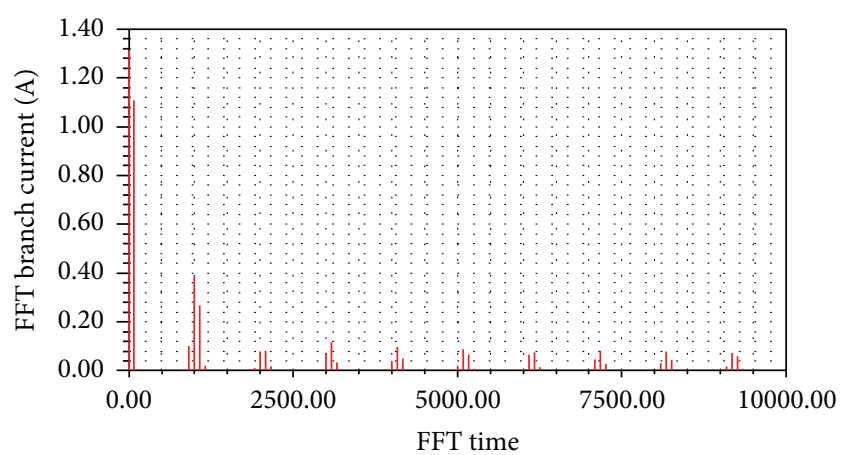

FIGURE 8: The FFT of DC link current (without filter).

the cause of desert effect on communication and radio systems. The high-frequency components of the DC link current can be reduced by using LC filter. The design of LC filter in the DC line is based on the spectrum of the DC link current. The LC filter weakens the high component of the DC link current. It is commonly used for low impedance sources and high impedance loads. In this study, the ideal voltage source with low impedance and high input impedance of the inverter is used. Therefore, LC filter would be a suitable choice. Equation (1) shows the LC filter design process:

$$
\begin{aligned}
2000 & =\frac{1}{2 \pi \sqrt{L C}} \\
C & =10 \mu \mathrm{F}, \\
L & =640 \mu \mathrm{H} \\
f_{c} & =\frac{1}{2 \pi \sqrt{640 \mu \mathrm{H} * 10 \mu \mathrm{F}}}=1989.43 \mathrm{~Hz} .
\end{aligned}
$$

Attenuation of the high-frequency components for frequencies above the cut-off frequency of the LC filter is effective. Since the standard capacitors and inductors are used to design filter, the exact cut-off frequency of the LC filter cannot be obtained. To filter the high-frequency components, especially above $2000 \mathrm{~Hz}$, the cut-off frequency that is obtained equal to $1989.43 \mathrm{~Hz}$ is considered. The value of the cut-off frequency of the LC filter is about $2000 \mathrm{~Hz}$. In practice, the self has series resistance. If the value of inductance is large, as a result, the resistance of the inductor will increase and the voltage drop will occur. If the value of inductance is $640 \mu \mathrm{H}$, the equivalent resistance of the chosen choke will have a relatively high value. Therefore, a choke, named SN203$640 \mathrm{M}-5.0 \mathrm{AV}$, is selected. The choke has $64 \mu \mathrm{H}$ inductance and $23 \mathrm{~m} \Omega$ equivalent resistance. Equation (2) shows the new LC filter design process:

$$
\begin{aligned}
2000 & =\frac{1}{2 \pi \sqrt{L C}} \\
C & =100 \mu \mathrm{F}, \\
L & =64 \mu \mathrm{H} \\
f_{c} & =\frac{1}{2 \pi \sqrt{64 \mu \mathrm{H} * 100 \mu \mathrm{F}}}=1989.43 \mathrm{~Hz} .
\end{aligned}
$$

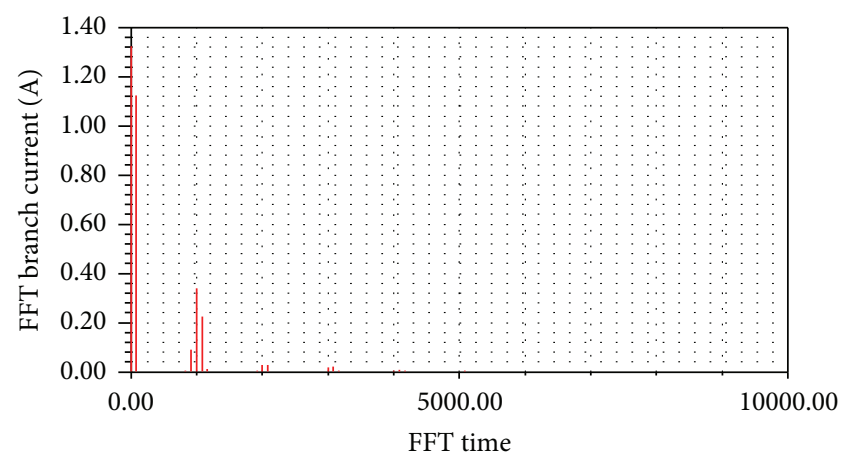

FIGURE 9: The FFT of DC link current (with LC filter).

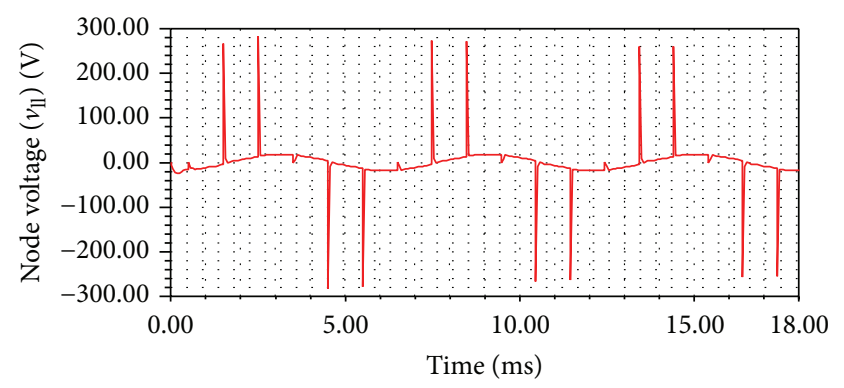

FIGURE 10: The line-to-line voltage waveform (with LCL filter).

Small changes appeared in the line-to-line voltage waveform, the phase current waveform, and the leakage current waveform. The LC filter weakened the high component of the DC source current, as seen in Figure 9. The simulation results showed that the inverter input current has high $d i / d t$ and therefore the MOSFET parasitic capacitance can conduct the high component of the current. Thus, it seemed necessary to add another passive element to the DC line. In order to reduce the input ripple current of the inverter, a series inductor is used. The series inductance must be chosen in such a way to lower the inverter input current ripple and prevent the effective voltage drop resulted from the inherent resistance of the inductor. According to the available inductors, a $160 \mu \mathrm{H}$ inductor (with series resistance of $32 \mathrm{~m} \Omega$ ) was selected according to the engineering experience. In this case, the input current ripple decreased from 2.5 to 0.7 ampere. The inductor, series with the inverter input, increased the reliability of the drive system. It reduces the amplitude of the inrush current, caused by short circuit of switches; as a result, the damage to the common DC bus, from which the other electronic and electrical systems are fed, will be less.

The line-to-line voltage, the leakage current, the FFT analysis of the DC link current, and the inverter input current are shown in Figures 10-13, respectively.

Due to the high equivalent inductance, the maximum amplitude of the leakage current increased significantly. It is necessary to use the capacitor bank in front of the AC line. In fact, by adding a capacitor bank, upon cessation of the motor phase current, the phase current flowed through the capacitor bank. Therefore, severe spikes in the voltage waveform due to the reaction of the inductance were reduced or eliminated. 


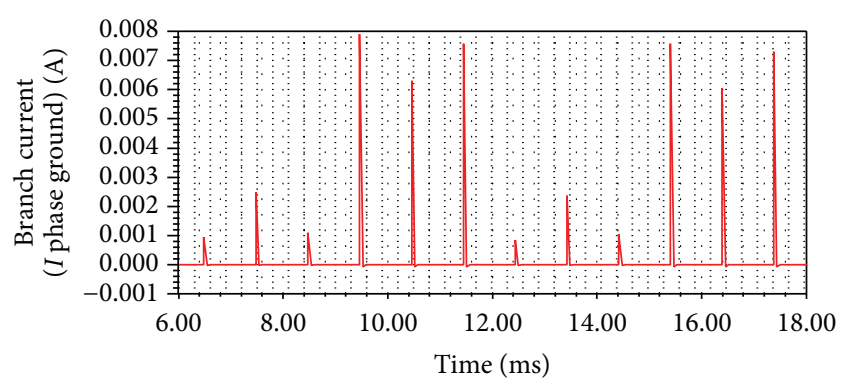

FIGURE 11: The leakage current (with LCL filter).

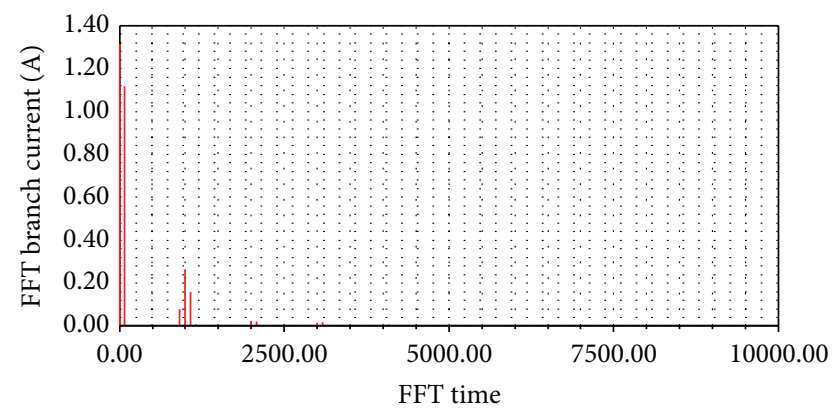

FIGURE 12: The FFT of DC link current (with LCL filter).

The capacitance value of the capacitor bank must be in such a way that does not cause interference with motor functions in the operating frequency motor (the impedance value of the capacitor bank must be high enough in the operating frequency motor) and the resonance frequency, as a result of the motor capacitor bank, must be far enough from the switching frequency. The amplitude of the current, drawn by the motor and the capacitor bank, may be of a high value due to the resonance. The equivalent circuit of the motor and the capacitor bank are shown in Figure 14 at different times. The phase motor is series with the capacitor and is the disconnected phase. It is required to adjust the value of the capacitor in such a way that the impedance of the middle branch for several multiples of the resonance would be too high (i.e., (3) must be satisfied). In addition, the impedance of the parallel branch consisting of two-series capacitors must be large enough (i.e., (4) must be satisfied). These requirements are applied in order to remove the effective current, drawn by the capacitor bank:

$$
\begin{aligned}
& 10 * 166.667<\frac{1}{2 \pi * \sqrt{\left(119 * 10^{-6}\right) * C}} \\
& C<76.6264 \mu \mathrm{F} \\
& \frac{1}{0.5 * \pi * 166.67 * C} \\
& >20 \sqrt{\left(0.233373^{2}\right)+\left(166.67 * 2 \pi * 119 * 10^{-6}\right)}
\end{aligned}
$$

$C<160 \mu \mathrm{F}$.

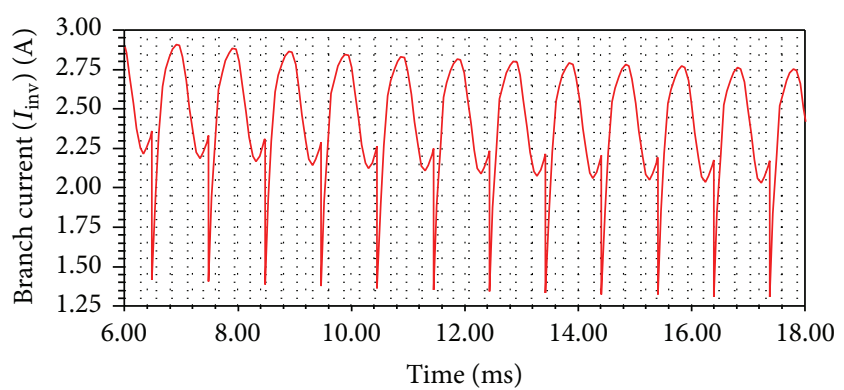

FIGURE 13: The inverter input current (with LCL filter).

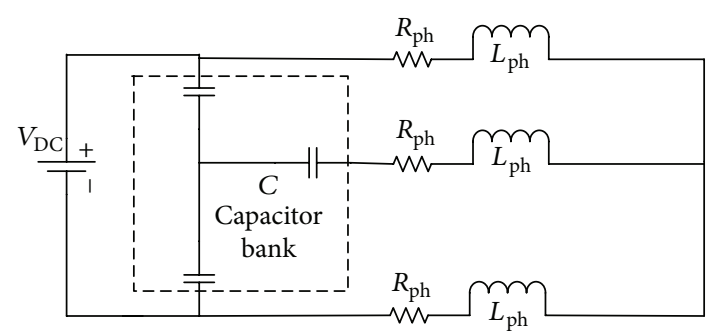

FIGURE 14: The equivalent circuit of the motor by the capacitor bank.

On the other hand, the resonant frequency of the capacitor must be far enough from the operating frequency of motor:

$$
\begin{aligned}
10 * 166.667 & <\frac{1}{2 \pi * \sqrt{\left(2 * 119 * 10^{-6}\right) * 0.5 C}} \\
C & <76.6264 \mu \mathrm{F} .
\end{aligned}
$$

Due to the application of the capacitor banks, the input current of the inverter will experience jumps. If the values of the capacitors are small, there will be higher amplitude jumps.

It is essential to select an appropriate capacitor bank. For this purpose, a $20 \mu \mathrm{F}$ capacitor bank has been considered. The line-to-line voltage waveform, the leakage current, the FFT analysis of the DC link current, the inverter input current, the 3-phase currents, and the current waveform of a power switch are obtained by finite element analysis. The mentioned results can be seen in Figures 15-20, respectively. A remarkable decrease in voltage jumps of the line voltage waveform is obvious. Due to the reduction in the amplitude of the jumps, the earth leakage current from the motor to the ground plane was significantly reduced, as can be observed in (7).

The amplitude of the leakage current was reduced from $400 \mu \mathrm{A}$ to $80 \mu \mathrm{A}$. The high-frequency components of the DC link current were effectively reduced. The three-phase current waveforms are still in the shape of a square. High $d i / d t$ at the switching time could cause damage to the power switches. Hence, it is essential to protect the power switches against high $d i / d t$ with the aid of a proper circuit. An RLD snubber is chosen, because the snubber circuits can reduce the leakage current. Due to the application of passive filters, its effect on 


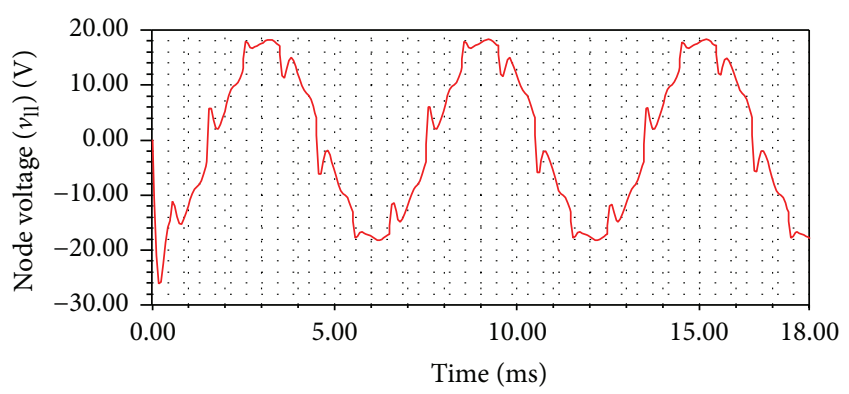

FIGURE 15: The line-to-line voltage waveform (with LCL filter and capacitor bank).

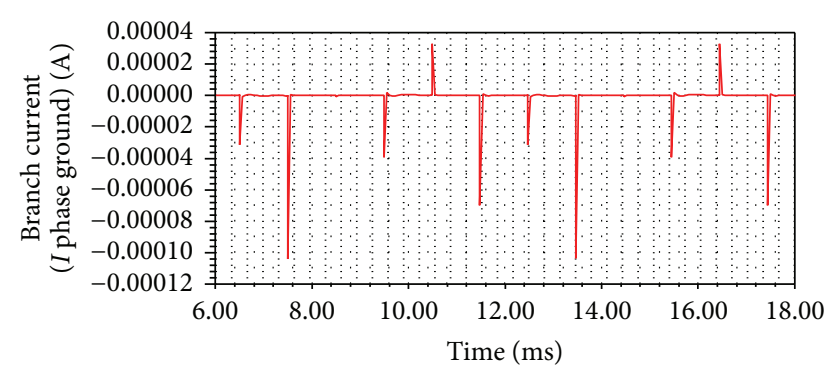

FIGURE 16: The leakage current (with LCL filter and capacitor bank).

the EMI reduction is small. The circuit of the selected snubber can be seen in Figure 21:

$$
\begin{aligned}
L_{s} & <\frac{P_{n}(=33 \mathrm{w})}{8000 *(2 \pi * 166.67) * 2.2^{2}}=0.814 \mathrm{nH} \\
L_{s} & =100 \mathrm{nH} \\
\frac{L_{s}}{R_{s}} & <2 T_{s} \\
R_{s} & >0.5 * \frac{100 * 10^{-9}}{5 * 10^{-6}}=0.01 \mathrm{ohm} \\
R_{s} & =200 \mathrm{mohm} .
\end{aligned}
$$

The amplitude of the current jumps was reduced from 25 (A) to 10.5 (A). In order to design the snubber, (6) to (8) are employed. The leakage current and a power switch current are shown in Figures 22 and 23. The snubber circuit affected the leakage reduction. By comparing Figures 16 and 22, it can be perceived that the maximum amplitude of the leakage current has been reduced from $100 \mu \mathrm{A}$ to $70 \mu \mathrm{A}$.

Finally, the overall structure of the drive system by the passive filter is shown in Figure 24. Each power switch is series with a snubber circuit. The DC line filter is placed in front of the DC link. The capacitor bank is in parallel with the terminals of the motor. Finally, the overall structure of the drive system by the passive filters is shown in Figure 24 .

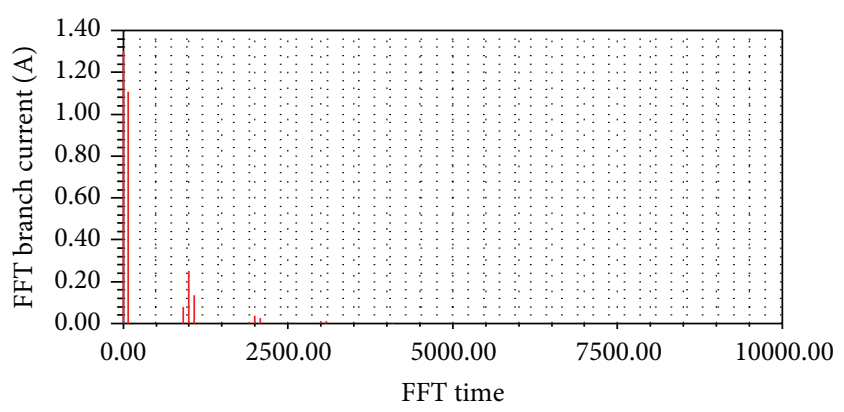

FIGURE 17: The FFT of DC link current (with LCL filter and capacitor bank).

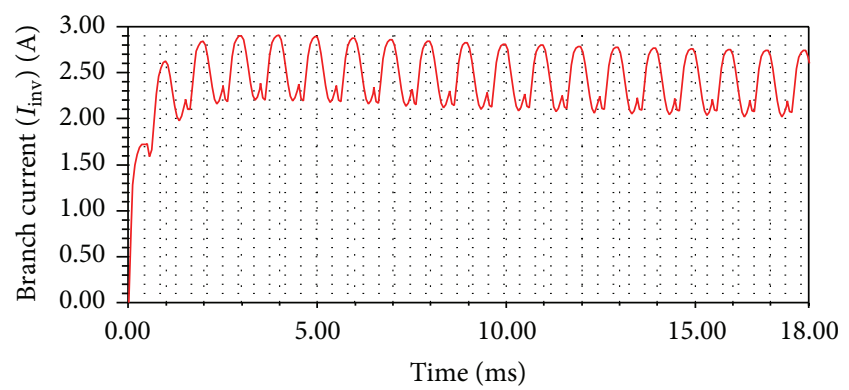

FIGURE 18: The inverter input current (with LCL filter and capacitor bank).

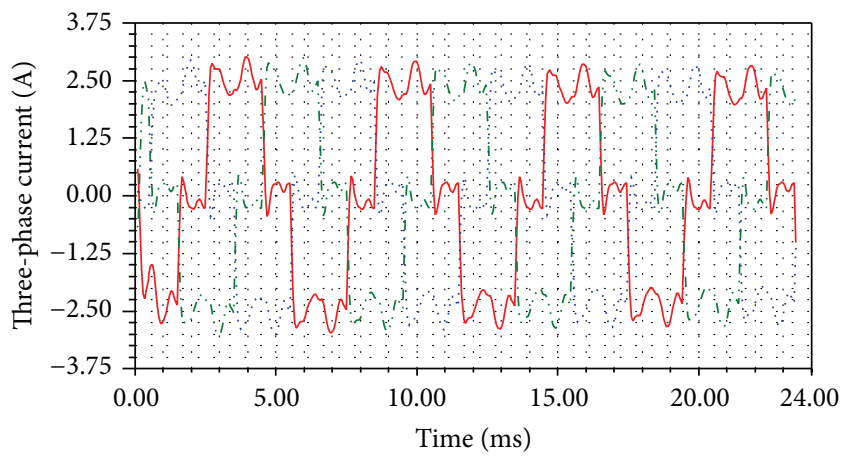

$$
\begin{aligned}
& \text { — Branch current }\left(I_{B}\right) \quad \text {...... Branch current }\left(I_{A}\right) \\
& \text { Setup 1: transient Setup 1: transient } \\
& \text {-..- Branch current }\left(I_{C}\right) \\
& \text { Setup 1: transient }
\end{aligned}
$$

FIGURE 19: The 3-phase motor currents (with LCL filter and capacitor bank).

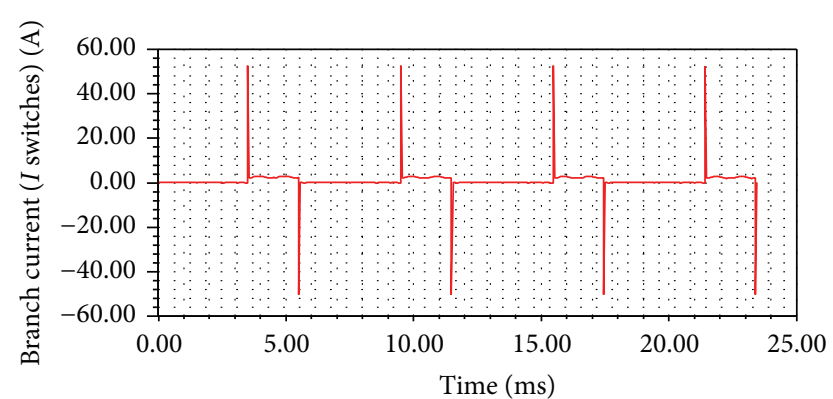

FIGURE 20: The current waveform of a switch (with LCL filter and capacitor bank). 


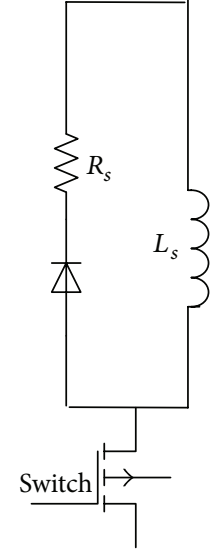

FIGURE 21: The overall structure of RLD snubber.

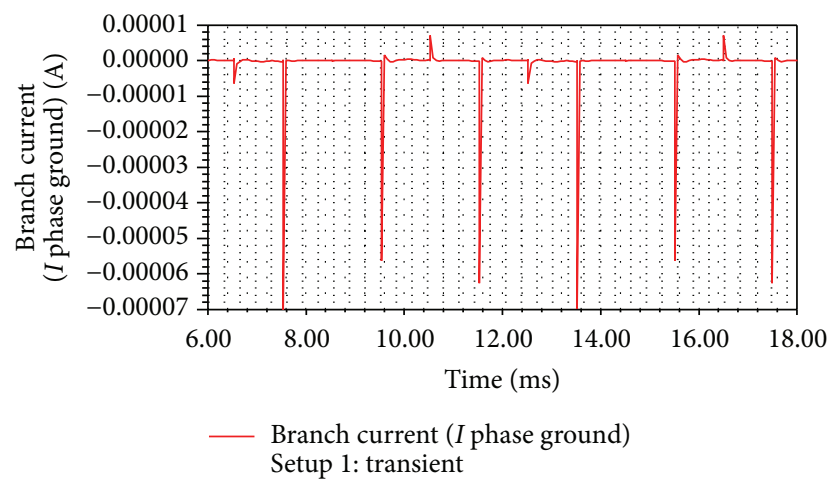

FIGURE 22: The leakage current (with LCL filter, capacitor bank, and RLD snubber).

\section{The EMI of BLDC Drive with Hysteresis Control}

The hysteresis control is widely used in controlling the AC motor in order to achieve fast dynamics, protect over current situations, and maintain the current in the form similar to the square waveform. In this control strategy, the measured load currents are compared with the references by using hysteresis comparators. Each comparator determines the switching state of the corresponding inverter leg, such that the load currents are imposed to remain within the hysteresis band and hence the frequency switching rises more than the traditional control state. The increase in the switching frequency increases the motor inductance reaction and consequently sudden changes in the line voltage, which cause the leakage current, are increased every $360^{\circ}$ of the operating drive system. The finite element results showed that the hysteresis control has caused high $d v / d t$ in the line-to-line voltage waveform and a high density leakage current. The line-to-line voltage, the leakage current, and the three-phase current are shown in Figures 25-27.

Due to the increased switching frequencies, the use of inductance in the inverter input significantly increased $d v / d t$. The inductance is series with the inverter input. Therefore, it was avoided in the hysteresis control mode. The designed LC

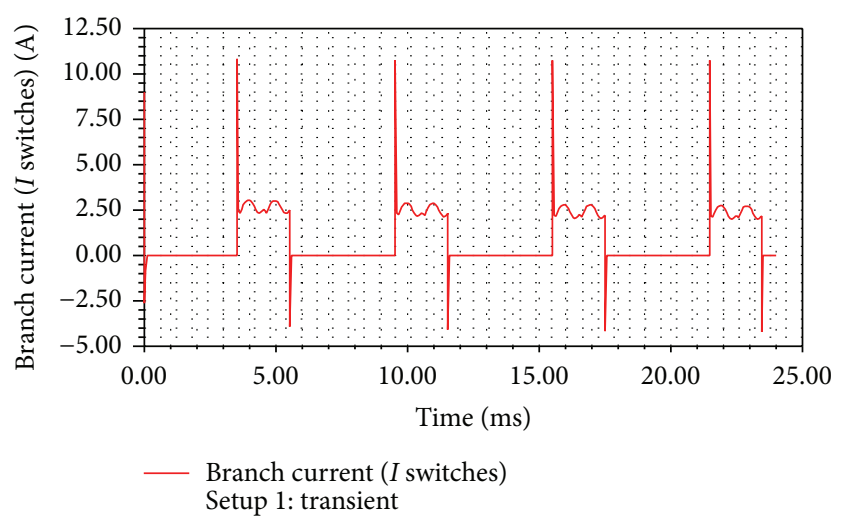

FIGURE 23: The current waveform of a switch (with LCL filter, capacitor bank, and RLD snubber).

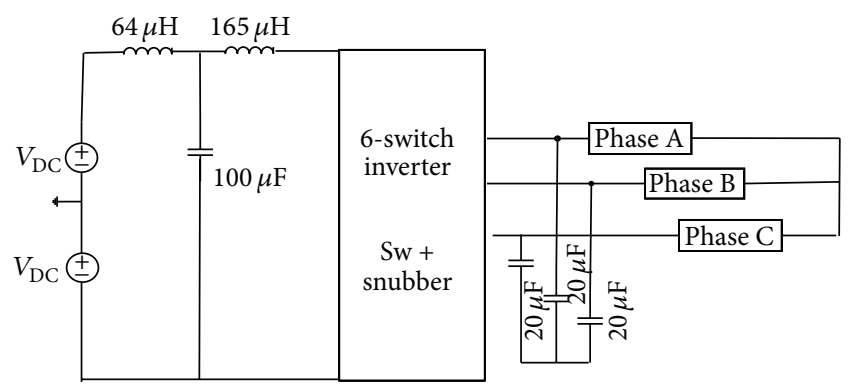

FIGURE 24: The overall structure of BLDC motor drive (with LCL filter, capacitor bank, and RLD snubber).

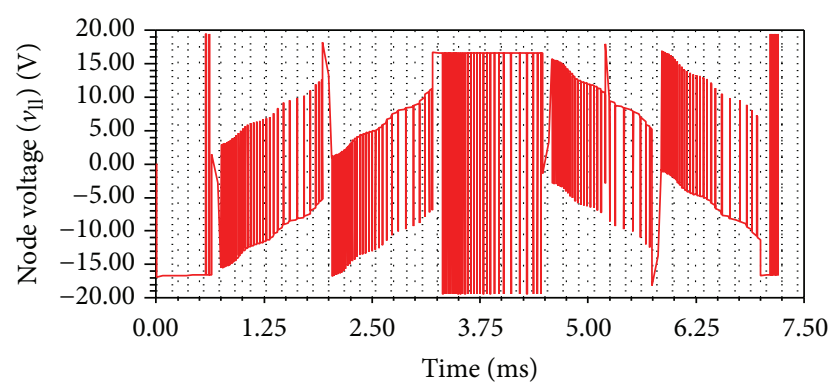

Figure 25: The line-to-line voltage waveform in hysteresis control mode (without filter).

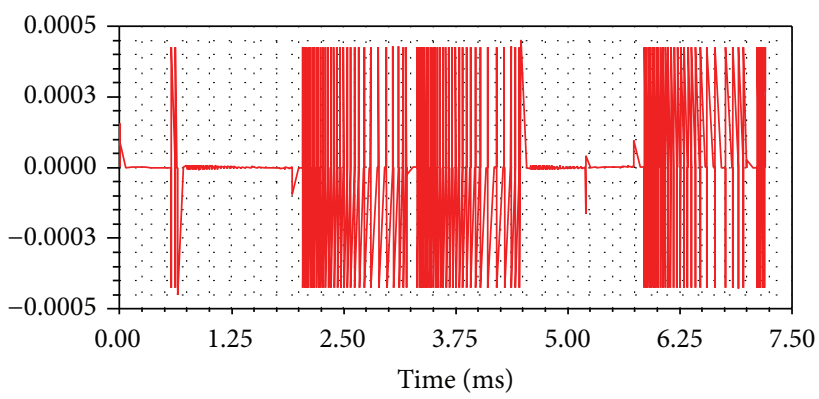

FIGURE 26: The leakage current in hysteresis control mode (without filter). 


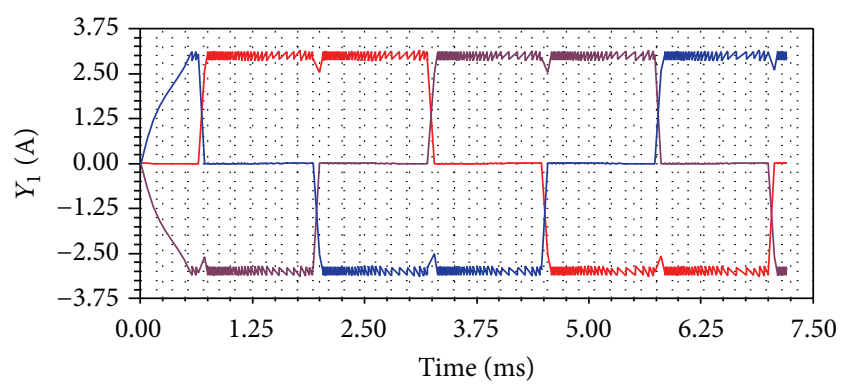

FIGURE 27: Three-phase current in hysteresis control mode (without filter).

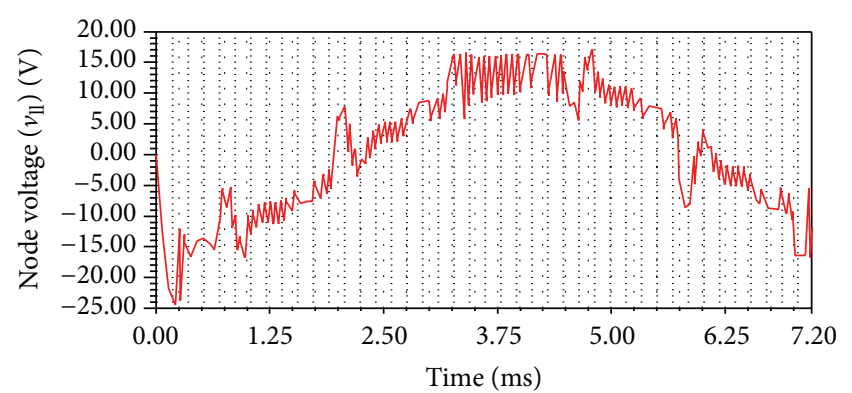

FIGURE 28: The line-to-line voltage waveform in hysteresis control mode (with filter).

filter and the capacitor bank are used to overcome the EMI. The line-to-line voltage and the leakage current can be seen in Figures 28 and 29. Due to the employment of the capacitor bank, the large voltage changes in rapid succession are reduced more effectively and so the maximum amplitude and density of the leakage current were reduced as well. The maximum amplitude of the leakage current was reduced from 450 to $180 \mu \mathrm{A}$.

The use of a hysteresis controller increased the highfrequency components, as can be observed in Figure 30. The high-frequency components up to $75 \mathrm{kHz}$ can be seen in Figure 30. When the designed filter is used in BLDC system, the high-frequency components were effectively weakened, especially for above $10 \mathrm{kHz}$ as seen in Figure 31.

\section{Conclusion}

In this paper, the proposed method has been implemented in order to overcome the electromagnetic noise on the basis of the high-frequency model of the motor-drive system using Maxwell's software package and the concepts of the EMI, and the structure and amounts of the proposed filter were extracted. In fact, the type and amount of passive elements and their placement were systematically investigated. At each step, the frequency spectra of the current and the leakage current were set as the criteria for assessing the impact of the strategies for reducing the noise.

Based on these two factors, the elements, placement, and the values of the selected passive elements in each step were determined. According to the results from the obtained

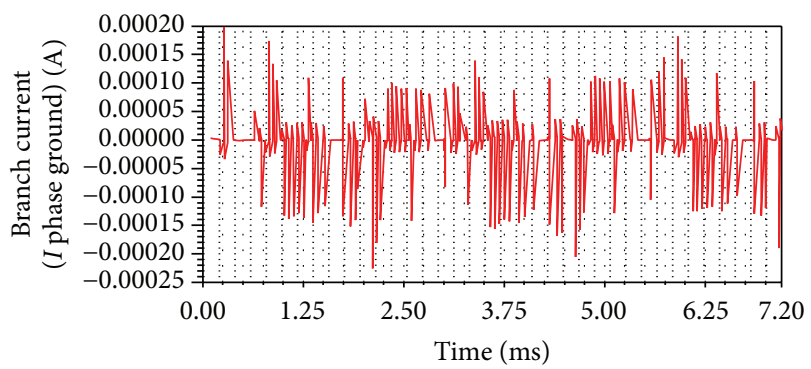

FIGURE 29: The leakage current in hysteresis control mode (with filter).

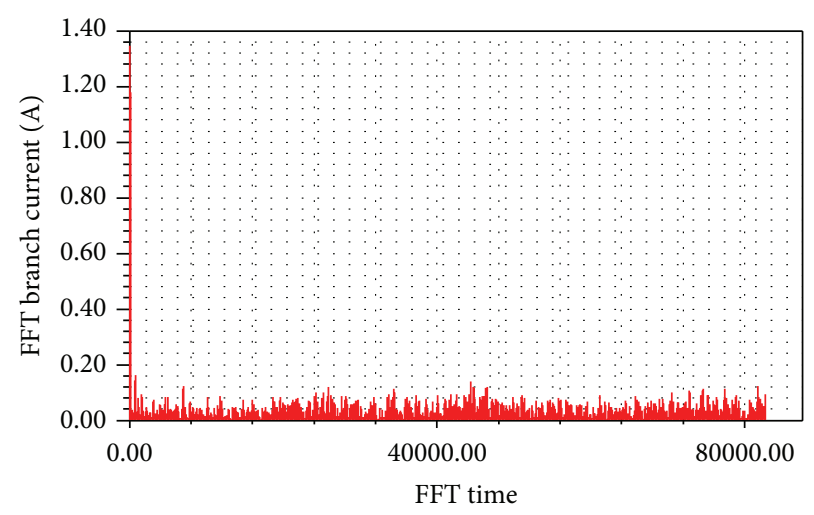

FIGURE 30: The FFT of DC link current in hysteresis control mode (without passive filter).

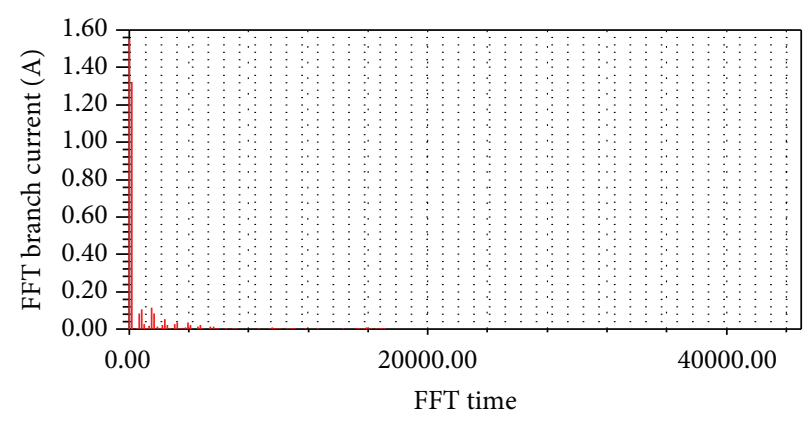

FIGURE 31: The FFT of DC link current in hysteresis control mode (with LCL filter and capacitor bank).

filter structure, there is a good potential in reducing electromagnetic noise.

Control methods, as the current hysteresis control, which increased the switching frequency, caused higher electromagnetic interference. It should be expressed that, in these cases, using appropriate filters is more necessary, and they have confirmed their effectiveness.

\section{Competing Interests}

The authors declare that they have no competing interests. 


\section{References}

[1] G. L. Skibinski, R. J. Kerkman, and D. Schlegel, "EMI emissions of modern PWM ac drives," IEEE Industry Applications Magazine, vol. 5, no. 6, pp. 47-80, 1999.

[2] J.-S. Lai, X. Huang, E. Pepa, S. Chen, and T. W. Nehl, "Inverter EMI modeling and simulation methodologies," IEEE Transactions on Industrial Electronics, vol. 53, no. 3, pp. 736-744, 2006.

[3] L. Ran, S. Gokani, J. Clare, K. J. Bradley, and C. Christopoulos, "Conducted electromagnetic emissions in induction motor drive systems part I: time domain analysis and identification of dominant modes," IEEE Transactions on Power Electronics, vol. 13, no. 4, pp. 757-767, 1998.

[4] F. Costa, E. Laboure, A. Puzo, and A. Pons, "Influence of the driver circuits in the generation and transmission of EMI in a power converter: effects on its electromagnetic susceptibility," European Power Electron Journal, vol. 5, no. 1, pp. 35-44, 1995.

[5] T. Rahimi, S. Y. Khangah, and B. Yousefi, "Reduction EMI due to di/dt and dv/dt DC and AC sides of BLDC motor drive," in Proceedings of the 5th Annual International Power Electronics, Drive Systems and Technologies Conference (PEDSTC '14), pp. 428-433, Tehran, Iran, February 2014.

[6] Y. Tang, H. Zhu, B. Song, J. S. Lai, and C. Chen, "EMI experimental comparison of PWM inverters between hard- and softswitching techniques," in Proceedings of the IEEE Power Electronics on Transportation Conference, pp. 71-77, IEEE, October 1998.

[7] H. Zhu, J.-S. Lai, A. R. Hefner Jr., Y. Tang, and C. Chen, "Analysis of conducted EMI emissions from PWM inverter based on empirical models and comparative experiments," in Proceedings of the 30th Annual IEEE Power Electronics Specialists Conference (PESC '99), pp. 861-867, Charleston, SC, USA, July 1999.

[8] S. Ogasawara and H. Akagi, "Modeling and damping of highfrequency leakage currents in PWM inverter-fed AC motor drive systems," IEEE Transactions on Industry Applications, vol. 32, no. 5, pp. 1105-1114, 1996.

[9] F. Wang, "Motor shaft voltages and bearing currents and their reduction in multilevel medium-voltage PWM voltage-sourceinverter drive applications," IEEE Transactions on Industry Applications, vol. 36, no. 5, pp. 1336-1341, 2000.

[10] J.-S. Lai, X. Huang, S. Chen, and T. W. Nehl, "EMI characterization and simulation with parasitic models for a low-voltage high-current AC motor drive," IEEE Transactions on Industry Applications, vol. 40, no. 1, pp. 178-185, 2004.

[11] T. Rahimi and S. H. Hosseini, "EMI consideration of high reliability electrical power subsystem (EPS) of satellite," in Proceedings of the 6th Annual International Power Electronics, Drive Systems, and Technologies Conference (PEDSTC '15), pp. 412-417, Tehran, Iran, February 2015.

[12] H. Akagi, H. Hasegawa, and T. Doumoto, "Design and performance of a passive EMI filter for use with a voltage-source PWM inverter having sinusoidal output voltage and zero commonmode voltage," IEEE Transactions on Power Electronics, vol. 19, no. 4, pp. 1069-1076, 2004.

[13] S. Ogasawara, H. Ayano, and H. Akagi, "An active circuit for cancellation of common-mode voltage generated by a PWM inverter," IEEE Transactions on Power Electronics, vol. 13, no. 5, pp. 835-841, 1998.

[14] S. Wang, Characterization and cancellation of high-frequency parasitics for EMI filters and noise separators in power electronics applications [Ph.D. thesis], Department of Electrical Engineering, Virginia Polytechnic Institute and State University, Blacksburg, Va, USA, 2005.

[15] R. Lai, Analysis and design for a high power density three-phase $A C$ converter using $\mathrm{SiC}$ devices [Ph.D. thesis], Department of Electrical Engineering, Virginia Polytechnic Institute and State University, Blacksburg, Va, USA, 2008.

[16] Y. Y. Maillet, High-density discrete passive EMI filter design for Dc-fed motor drives [M.S. thesis], Department of Electrical Engineering, Virginia Polytechnic Institute and State University, Blacksburg, Va, USA, 2008.

[17] A. Carrubba, M. C. Di Piazza, G. Tine, and G. Vitale, "Evaluation of common mode disturbance mitigation devices in $\mathrm{AC}$ motor drives through HF modeling," in Proceedings of the IEEE International Symposium on Industrial Electronics, pp. 23152320, Montreal, Canada, July 2006.

[18] Y. Maillet, R. Lai, S. Wang, F. Wang, R. Burgos, and D. Boroyevich, "High-density EMI filter design for dc-fed motor drives," IEEE Transactions on Power Electronics, vol. 25, no. 5, pp. 1163$1172,2010$.

[19] M. C. Di Piazza, M. Luna, and G. Vitale, "EMI reduction in DCfed electric drives by active common-mode compensator," IEEE Transactions on Electromagnetic Compatibility, vol. 56, no. 5, pp. 1067-1076, 2014

[20] X. Gong and J. A. Ferreira, "Comparison and reduction of conducted EMI in SiC JFET and Si IGBT-based motor drives," IEEE Transactions on Power Electronics, vol. 29, no. 4, pp. 17571767, 2014.

[21] Hysteresis Control Circuit Diagram, Electrical and Computer Engineering Department, University of Missouri-Rolla, Rolla, Mo, USA, 2002.

[22] R. Carlson, M. Lajoie-Mazenc, and J. C. D. S. Fagundes, "Analysis of torque ripple due to phase commutation in brushless DC machines," IEEE Transactions on Industry Applications, vol. 28, no. 3, pp. 632-638, 1992.

[23] W. Chang-hee, S. Joong-Ho, and I. Choy, "Commutation torque ripple reduction in brushless DC motor drives using a single DC current sensor," IEEE Transactions on Power Electronics, vol. 19, no. 2, pp. 985-990, 2004.

[24] A. Carrubba, M. C. Di Piazza, G. Tine, and G. Vitale, "Evaluation of common mode disturbance mitigation devices in AC motor drives through HF modelling," in Proceedings of the IEEE International Symposium on Industrial Electronics, pp. 23152320, Montreal, Canada, July 2006. 

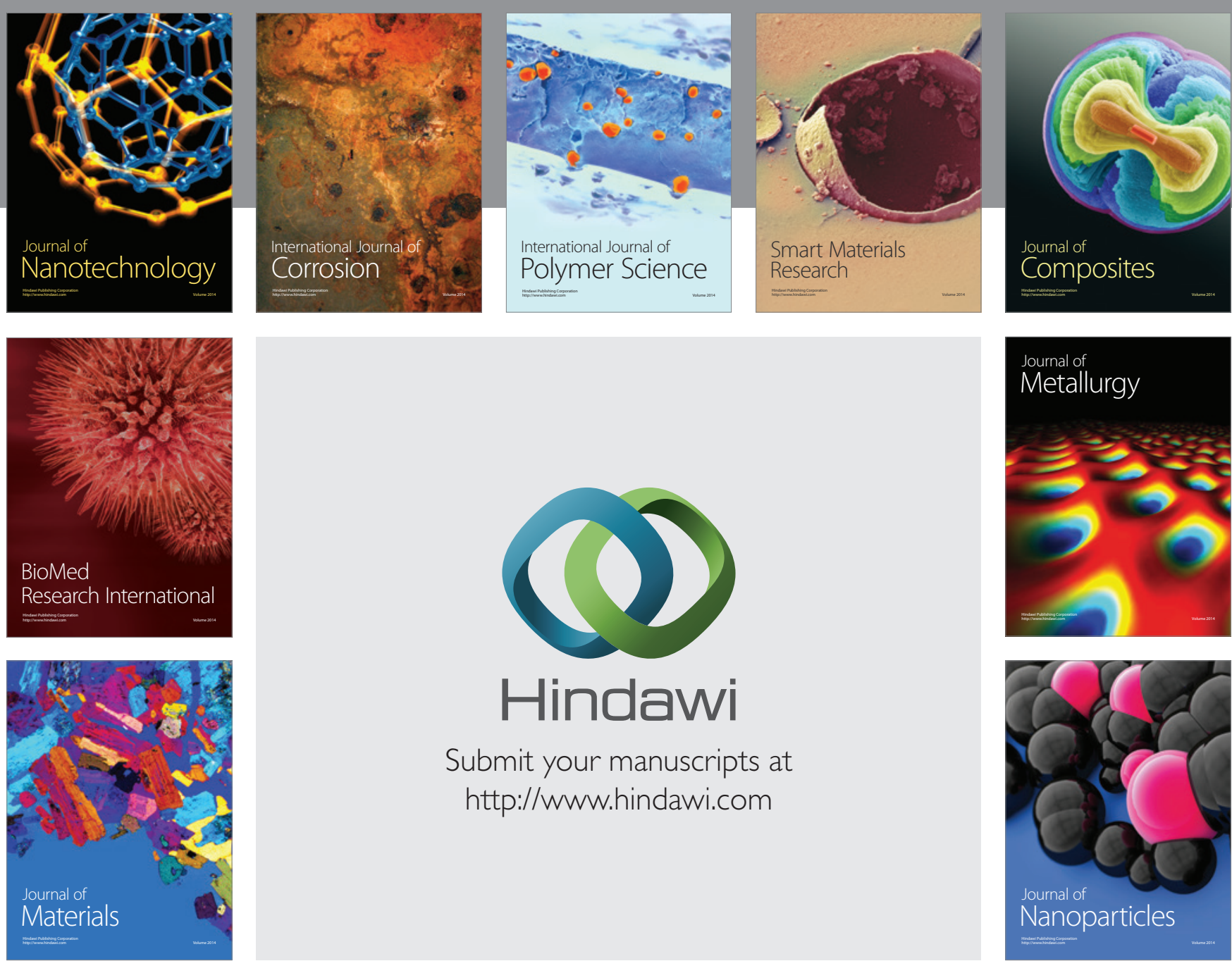

\section{Hindawi}

Submit your manuscripts at

http://www.hindawi.com

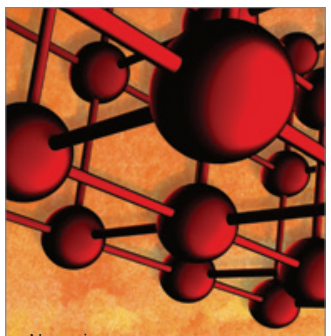

Materials Science and Engineering
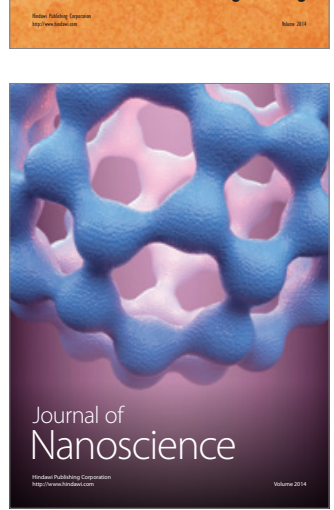
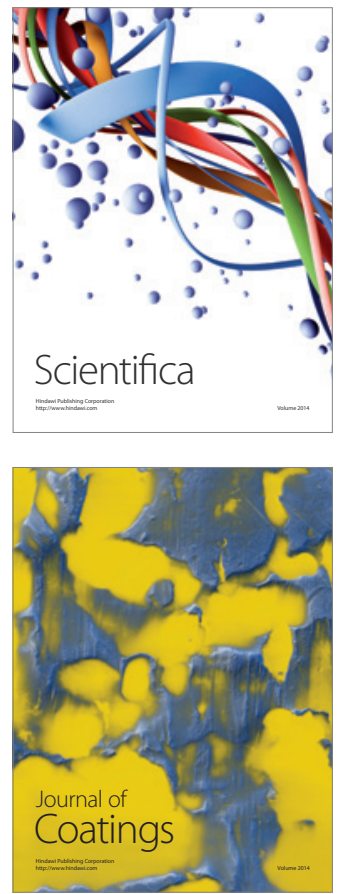
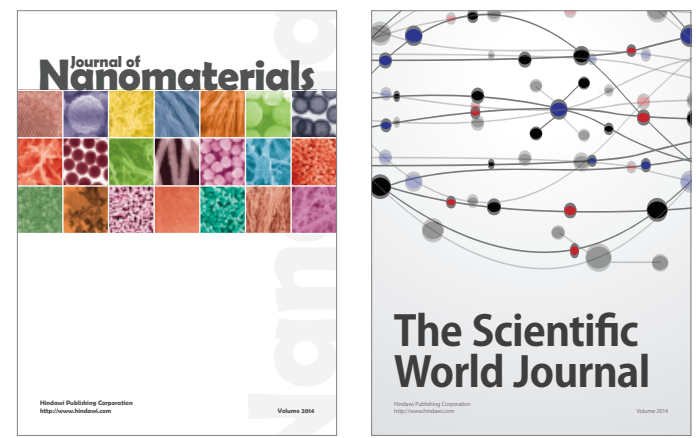

The Scientific World Journal
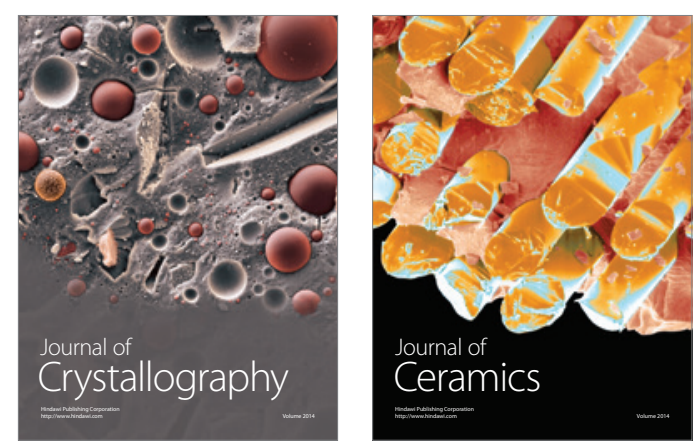
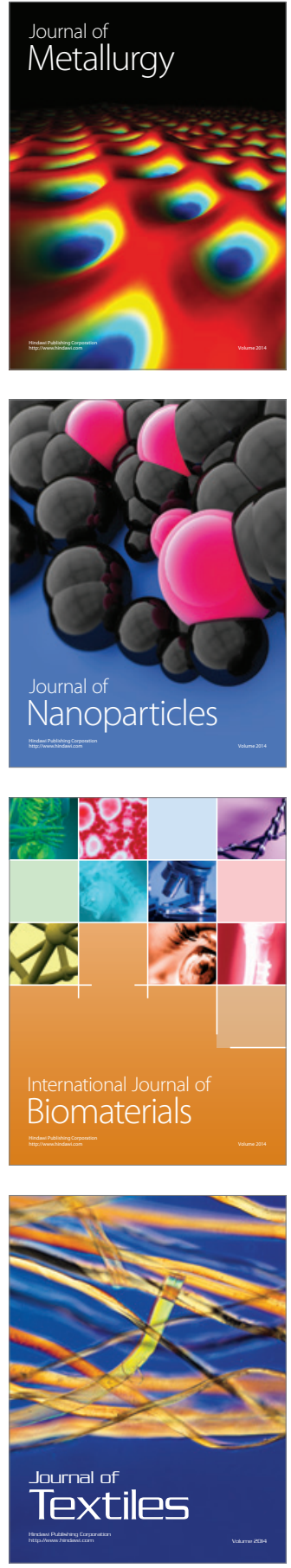